ARTICLE

https://doi.org/10.1057/s41599-019-0331-9

\title{
An Aristotelian interpretation of practical wisdom: the case of retirees
}

Peter Massingham ${ }^{1 \star}$

\begin{abstract}
This paper aims to improve understanding of the concept of practical wisdom. The theoretical lens used is Aristotle's practical rationality or 'phronesis'. Researchers argue that practical wisdom should be used as an organising framework for professional knowledge. Aristotle believed that practical wisdom as the highest intellectual virtue. Phronesis is the complicated interactions between general (theory) and practical (judgement). The contribution of this paper is to discuss the properties of practical wisdom and how they interact based on an interpretation of retirees' knowledge. The paper summarises in-depth face-toface interviews with nine retirees, i.e., nine separate case studies. A structured interview guideline based on a conceptual framework derived from literature was used to examine the nature of retirees' practical wisdom. People with wisdom make better decisions. Whereas episteme's technical knowledge may address complicated tasks, techne's wisdom enables people to resolve truly complex tasks. Techne provides personal judgement which enables the professional to judge their actions from an external and internal perspective. Knowing that others and the individual themselves are happy with the quality of their work creates a morality that enables an inner calm and personal satisfaction leading to eudaimonia (feeling happy about life). People with wisdom behave differently. Phronesis's cognitive properties create awareness of the knowledge that may be trusted to be seen to be behaving normally or appropriately in the organisation. The global population is ageing. This has implications for future workforce planning as experience is lost and capability gaps emerge. Retires may represent a valuable source of knowledge to help address this gap. The results are limited to nine individual case studies and four disciplines. The findings provide exciting opportunities for further research. The conceptual models may be further investigated with retirees in other disciplines.
\end{abstract}

\footnotetext{
${ }^{1}$ School of Management, Operations, and Marketing Faculty of Business, University of Wollongong, Northfields Avenue, Wollongong, NSW 2522, Australia. *email: peterm@uow.edu.au
} 


\section{Introduction}

his paper aims to improve understanding of the concept of practical wisdom. There has been renewed interest in Aristotle's concept of practical knowledge (Ellett, 2012), and how a better grasp of his ideas might further inform the development of organisation studies (Tsoukas and Cummings, 1997). In Aristotle's framework, practical wisdom is the highest intellectual virtue (Tsoukas and Cummings, 1997). The contemporary hierarchy of intellect typically transitions from data to information, knowledge, and wisdom through an increase of connectedness and understanding (Ackoff, 1989). Researchers argue that practical wisdom should be used as an organising framework for professional knowledge (Higgs, 2012, p. 77).

The theoretical lens used is Aristotle's practical rationality or 'phronesis' (see Ellett, 2012, p. 12). According to Aristotle, dealing successfully with practical matters, such as in work, requires practical knowledge (Tsoukas and Cummings, 1997). Wisdom appears to be gained from a process of pedagogical thinking and reasoning (Ellett, 2012, p. 12). It appears to involve a cognitive process of reflecting on practice in the process of doing; with internal questions of 'what I am doing?' and 'can I do this better?' It has a praxeological style of reasoning (Hacking, 2002, p. 3), which extends beyond the theory and practice debate (Bredillet, et al., 2014, p. 19). Praxeology is defined as study or science of human actions and conduct, i.e., praxis (Hacking, 2002, p. 3). Ellett (2012, p. 15) distinguishes between theoretical reason, i.e., what one should believe, and practical reason (or rationality), i.e., how one should act. This cognitive process involves more than adapting discipline knowledge to suit the operational context, i.e., action learning. Action learning is when theory and practice inform each other as the individual applies theories in the environment (Revans, 1980). Practical wisdom has an ethical virtue known as Eudaimonia, which is 'the capacity to act based on reasoning with regard to things that are good or bad for humanity' (Thompson, 2017, p. 212). One might know what is the practically reasonably way to act, but choose not to (Ellett, 2012, p. 12).

A way to examine the praxis of the cognitive choices involved in practical wisdom is by deconstructing practice knowledge. Practice knowledge is 'the sum of the knowledge used in practice, including theorisation, and experiential knowledge' (Higgs, 2012, p. 77). In organisation studies, the former is discipline knowledge e.g., university qualifications; while the latter is knowledge gathered from professional practice experience (Higgs, 2012, p. 77), or what Ellett (2012, p. 14) calls 'embodied social practice', and knowledge gained from personal experience (personal knowledge), (Higgs, 2012, p. 77), or what Ellett (2012, p. 14) calls 'deliberative judgement'. The range of activities and experience which define professional practice have 'two intertwining dimensions knowledge and reasoning' (Higgs, 2012, pp. 77-78), or what Ellett (2012, p. 14) calls virtue, i.e., Eudaimonia. In these two dimensions, knowledge includes 'procedural, artistic, ethical, and propositional; while reasoning includes judgement, wisdom, metacognition, and intuition' (Higgs, 2012, p. 78). This typology makes wisdom only a sub-set of professional practice. To return to Aristotle's view of practical wisdom as the highest intellectual virtue; we are reminded that phronesis is the complicated interactions between general (theory) and practical (judgement) (Ellett, 2012, p. 14). There have been few empirical studies which deconstruct practical wisdom (Thompson, 2017). The contribution of this paper is to discuss the properties of practical wisdom and how they interact based on an interpretation of retirees' knowledge.

Based on detailed case studies with nine retirees across four disciplines, this paper develops a rich narrative about the knowledge accumulated over a life-time and whether this might be classified as practical wisdom. Retirees were chosen due to their experience. The DIKW hierarchy places wisdom above knowledge due to the impact of experience (Ackoff, 1989). While the relationship between knowledge and experience is controversial, researchers have argued that the difference between knowledge and wisdom is experience gathered from accumulated learning and understanding (Faucher et al., 2008). Experience accumulates with age, i.e., time in the job, and, therefore, it is reasonable to assume that people who have retired from the workforce have accumulated the most experience. The study situated retirees' professional practice within the context of their discipline knowledge and their reasoning in terms of their reflection on what worked for them throughout their life-time. The praxis was retirees' reflection on a career about the most reasonable way to act, and whether this followed discipline knowledge (i.e., theorisation) or reasoning based on experiential knowledge. The paper proceeds to conceptualise about this reflective process with the aim to discover more about the nature of practical wisdom. The paper proceeds with a brief literature review, methodology, and then the research findings.

\section{Previous research on wisdom}

Professional practice knowledge. Research on wisdom is necessary because it has a significant impact on success and impact at individual, organisational and community levels' (Rowley, 2006, p. 1247). Research has found that wisdom comes from the practice of doing work itself (Ellett, 2012, p. 12). For many years, the literature has agreed that research and practice produce distinct forms of knowledge (Tsoukas and Cummings, 1997). Professionals progress from novice to master in the course of practising their craft. How this occurs requires deconstructing professional practice.

The theory of professional practice makes explicit distinctions between technical and practical knowledge (Habermas, 1971). Habermas (1971) distinguished between technical knowledge as formal, explicit, propositional, and discursive; and practical knowledge as tacit and embodied in action. This is similar to Aristotle's distinctions between scientific knowledge (episteme) and craft knowledge (techne). Episteme (Habermas's technical knowledge) consists of deductions from basic principles, and techne (Habermas's practical knowledge) which is about how to make things (see Tsoukas and Cummings, 1997).

Episteme. In organisation studies, episteme is professional practice knowledge. Practice is 'doing, knowing, being, and becoming' (Higgs, 2012, p. 75). A professional is distinguished by 'the capacity to make sound judgements in the absence of certainty' (Higgs, 2012, p. 79). Professionals associate with their discipline, e.g., engineering or teaching, and their episteme begins with their qualifications, i.e., what they learned at university. Professional practice is the 'enactment of a group of people in a profession or occupation who serve or contribute to society' (Higgs, 2012, p. 75). In this sense, professional practice knowledge represents a higher level of knowing than other practical knowledge due to the quality of decisions it enables. Good practice involves complex decision making. Good decisions are defined by whether the proposed actions may be supported by a 'variety of evidence' (Higgs, 2012, p. 79). Professional practice is based on 'specific intentions and values (and) is often grounded in assumptions rather than conscious decisions' (Higgs, 2012, p. 76). These assumptions are 'constructed by individuals and groups' (Higgs, 2012, p. 76). This construction begins at university with theoretical knowledge (Ellett, 2012) and, therefore, is situated in literature (Higgs, 2012). It is situational (Higgs, 2012), in the sense 
that professionals agree on a reason to exist, i.e., a practical need, and a set of standards, i.e., defined competence (Ellett, 2012). This cognitive process is deliberative judgement: theoretical reasoning governed by the rules of formal deductive logic (Ellett, 2012).

Techne. In organisation studies, techne is social practice knowledge. This idea is built on a constructionist interpretation of knowledge where the professional's theoretical knowledge (episteme) is adapted to the unique 'social, cultural, and historical context' of their organisation (Higgs, 2012, p. 80). Praxis is a form of practice that is 'ethically informed, committed, and guided by critical reflection of practice tradition's and one's own practice' (Higgs, 2012, p. 75). It is the 'complex interaction of general and particulars' (Ellett, 2012); where the general is professional standards (the episteme tradition), and the particulars are personal judgement (the techne practice). Professional practice is constantly evolving (Higgs, 2012) as professionals are given autonomy, i.e., to practice judgement (Ellett, 2012), and standards are revised and improved (Higgs, 2012). Professionals, therefore, have scope to build upon existing practice by using their individual judgement to improve upon theory and standards. This cognitive reasoning is informed practice: where professionals understand the nature of their knowledge and its creation (episteme) and can adapt this to their own practice model (techne) that 'guides and gives credibility' to their knowledge (Higgs, 2012, pp. 79-80).

Phronesis. In organisation studies, phronesis is morally virtuous decisions. This is Aristotle's idea of practical rationality (see Ellett, 2012: 12), which is knowledge that helps with practical matters such as actions associated with professional practice (Tsoukas and Cummings, 1997). Wisdom emerges from a combination of 'pedagogical thinking and reasoning' (Ellett, 2012, p. 12). Practice wisdom emerges through 'experiences, learning, reflecting, critical dialogue, making theories, and creating and testing hypotheses'. (Higgs, 2012, p. 75). According to Tsoukas and Cummings, (1997), Aristotle believed that both craft knowledge (techne) and practical wisdom (phronesis) are types of practical knowledge, in contrast to scientific knowledge (episteme) which is theoretical. The difference between techne and phronesis is action and production. Techne is used to produce things and the object produced is the end in itself. Phronesis is used to act. There is a relationship between acting and the standards against which the acting is judged (Tsoukas and Cummings, 1997). These standards do not apply to the production of objects. Techne is judged by the quality of the product itself, and by the steps taken to achieve the product, i.e., the technical processes. The standards used to judge actions associated with phronesis are based on the most reasonable way to act.

Phronesis has 'both an intellectual virtue and an ethical virtue' (Eikeland, 2008, p. 53). For Aristotle, practical knowledge and moral virtues go together: it is impossible to be practically wise without being good (Van de ven, A.H., and Johnson 2006). The cognitive reasoning which distinguishes phronesis from techne is knowing the right values (Tsoukas and Cummings, 1997). These values are determined by the professional's sense of Eudaimonia. Eudaimonia requires 'excellence of character', i.e., virtue (Bredillet, et al., 2014, p. 21). It is social practice meaning that if a person knew the most reasonable way to act, they would do so (Ellett, 2012). These actions are guided by values associated with a sense of what is the right thing to do for humanity, being a good person, and living a good life.

For Aristotle, techne is subordinate to phronesis (Van de ven, A.H., and Johnson 2006). Eudaimonia also involves intellectual excellence, i.e., reason and rational activity (Bredillet et al., 2014: p. 21). This reasoning involves both cognitive and affective dimensions. The cognitive dimension is knowing how to achieve Eudaimonia. It is possible for a professional to know the right values without knowing how to achieve them in practice (Van de ven, A.H., and Johnson 2006). The affective dimension is knowing why to achieve Eudaimonia. It is possible for a professional to know how to achieve Eudaimonia but choose not to (Van de ven, A.H. and Johnson, 2006). This decision involves more than motivation to do the right thing. Phronesis does not have motivational hedonism and rational egoism (Ellett, 2012). The moral virtue of phronesis is not about personal gain, rather it is a higher goal loosely described as the profession's ends, or society's well-being (Ellett, 2012). Therefore this higher motivation has both cognitive and affective elements. The former is the ability to deliberate well and make good judgements, while the latter is about attitude, and choosing to act on this judgement (Ellett, 2012).

\section{Conceptual framework}

Figure 1 presents a conceptual framework derived from the brief literature review. On the left hand side is the practical wisdom constructs, i.e., episteme, techne, and phronesis. Next are the dimensions, which summarise the praxeological style of reasoning (Hacking, 2002, p. 3) associated with each construct. Then comes the professional practice properties which combine knowledge and reasoning (Higgs, 2012, pp. 77-78); to create the 'possibilities of individual knowing' (Chia, 1995, p. 582); and a 'socially conditioned response to a pre-established ordering of things' (Chia, 1995 , p. 582). On the right hand side is the type of knowledge which is the outcome for the professional as they move across each of the constructs.

Table 1 provides definitions of the ideas presented in Fig. 1, along with summary literature

\section{Research methodology}

This paper is based on an empirical research study of knowledge from practice (see Kondrat, 1992). The study followed Thompson's (2017, p. 215) goal with his wisdom research to 'explore manager's self-understanding of practical wisdom and to identify the ontological activity present in their managerial decision making'. Therefore, the study sought to capture the retirees' selfunderstanding of their practical wisdom, but not about practical wisdom as a concept, rather about what they knew about workrelated knowledge, which might then be articulated as practical wisdom. The abstraction of the retirees' practical wisdom (e.g., see Fig. 1 and Table 2 in particular) was the author's.

The study consisted of a series of activities to capture and share retirees' knowledge with younger people. The knowledge elicitation process adopted Gavrilova and Andreeva's (2012) analystmediated knowledge acquisition method. This included an analyst-leading structured $2 \mathrm{~h}$ face-to-face depth interviews with retirees; followed one month later with an expert-analyst collaborating role game between retirees and younger people. The research activities captured retirees' knowledge about their careers. Instead of beginning with definitions of knowledge "for" practice, the questions in the study were designed to define knowledge "from" practice (see Van de ven, A.H., and Johnson 2006). This is a qualitative research method designed to discover 'practical rationality' (see Macklin and Whiteford, 2012, p. 87).

Practical rationality emerges from the interview by 'evaluating multiple factors in concrete situations' (i.e., retirees' reflection on work situations), and 'taking into account people's beliefs, interests, and norms' (i.e., what worked for the retiree), in 'addition to the specific demands of a sound practical judgement' (i.e., reflection on why it worked for them) (Macklin and 

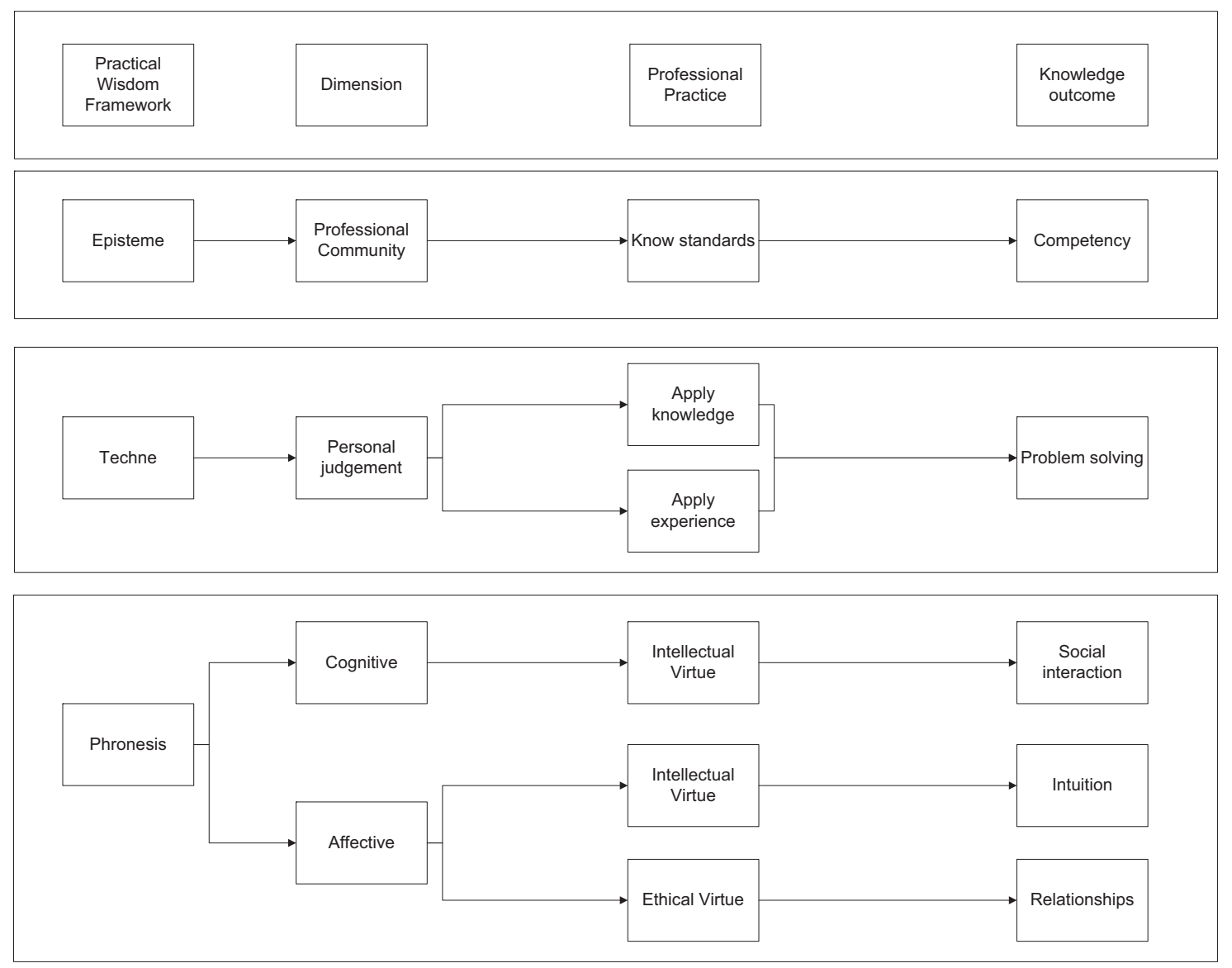

Fig. 1 Conceptual framework

Whiteford, 2012, p. 87). This approach 'reverses the usual order of business, which privileges formal-technical scientific knowledge and assigns a derivative status to the "practical" as a secondary way of knowing' (Van de ven, A.H., and Johnson 2006, p. 805). This switch produces a research outcome that defines practical wisdom as a distinct way of knowing rather than a subset of scientific knowledge, i.e., episteme (see Van de ven, A.H., and Johnson 2006). In doing so, the research method seeks phronesis about professional practice. In discovering phronesis from respondents, the research 'does not involve pure technique or pure intellect, but a capacity to intuit and a capacity to draw on emotions' (Macklin and Whiteford, 2012, p. 92). During the faceto-face depth interviews, the respondent (retiree) was encouraged to reflect on the life-time of experience gathered over their career and to explain what worked for them. In this way, the interview was designed to recognise the value of the retiree as an individual, so it was an empowering experience for them. The intuition which emerged in the retiree's reflection was situated within this positive emotional context, however, the retirees' were also encouraged to discuss lessons learned, e.g., mistakes, as part of this reflection.

Practical wisdom research is 'case-based' (each retirees' unique life journey), 'customised to particular contexts' (discipline and job), and 'not easily susceptible to empirical generalisation' (Macklin and Whiteford, 2012, p. 92). This explanation justifies the research method used to elicit the retirees' practical wisdom. Asking retirees to articulate the knowledge gained over their career is not amenable to survey research (e.g., 7-point likert scales). Life journeys cannot be summarised by ticking a box. For example, the praxis of retirees' reflection on how they applied episteme to become their unique techne requires a rich narrative.
The method of depth interviews followed by group discussion with inquisitive younger people was suitable for eliciting this narrative. As stated above, the interpretation of the narrative in terms of an Aristotelian conceptualisation of practical wisdom was the author's. This process enabled generalisations about the nature of the retirees' practical wisdom from a constructivist epistemological perspective.

The nine cases used in this study represented nine retirees from four disciplines: engineering, teaching, nursing, and business. In tackling the challenges listed above; the research method had three guiding principles retirees' reflection on: (1) practice knowledge (episteme), (2) good decision making (techne), and (3) moral virtue (phronesis). For example, reflections on moral virtue involved personal knowledge about living one's life and the kind of person that one is (Macklin and Whiteford, 2012, pp. 91-93). This approach requires using dialogical and empathetic approaches to ask 'how' and to analyse both the narrative and the tacit elements such as emotions, habits, skills, and actions (Thompson, 2017 , p. 215). In the research presented in this paper, the narrative was the depth interview; the tacit dimension emerged in the focus group; and emotions surfaced in how retirees felt about work, habits (technical), skills (cognitive), actions (why they did it this way).

\section{Episteme: professional community}

Technical competencies are the basic building blocks of jobrelated knowledge. The discovery of episteme explored the retirees' perspective on their discipline, e.g., engineering or nursing, how their education and qualifications was useful in the act of performing their work and benefited their career. 


\section{Table 1 Practical wisdom conceptualisation}

$\begin{array}{lll}\text { Construct } \quad \text { Concept Literature } & \end{array}$

- Episteme - Professional community

Techne

Techne

Phronesis: cognitive

Phronesi: affective

Phronesis: affective

Phronesis: affective

Phronesis: affective virtue: behavioural dimension dimension

Ethical virtue: morality dimension

Personal judgement: cognitive dimension

Personal judgement: practical dimension

Intellectual virtue: emotional dimension

Ethical virtue: relational dimension
- Kondrat (1992) argues that the starting point for eliciting knowledge about practice should be empirical questions such as:

- What knowledge does the practitioner of an occupation or profession use, and how does he or she obtain it?

- What does the practitioner think, and how does he or she go about constructing thought and action?

- What does the competent practitioner know, and how does he or she go about knowing "in" practice? (after Van de ven, A.H., and Johnson 2006, p. 805)

There is a fundamental difference between being knowledgeable and being wise (Bierly et al., 2000). Whereas being knowledgeable helps solve complicated problems, wisdom is the capacity to resolve complex problems (Minsky, 1985). Wisdom, therefore, can resolve complexity

Pinheiro et al. (2012) explain that organisational wisdom is the organisation as a whole solving existing problems, i.e., collective knowledge. They develop a model of organisational wisdom with (a) inputs: data, information, and knowledge, learning creativity and innovation; (b) knowledge management activities: creation, relearning, memory, knowledge loss, and emotional intelligence; and (c) organisation actions: problem solving (efficiency), response (effectiveness), and value creation. It involves judgements about skilful knowing. Wisdom, therefore, has organisational value

Bierly et al. (2000) argued that wisdom is about judgement, particularly in terms of moral conduct. Science can 'tell us how to do things but not whether any specific thing that can be done, ought to be done' (Bierly et al., 2000, p. 603). Wisdom has been defined as 'the capacity to put into action the most appropriate behaviour, taking into account what is known (knowledge) and what does the most good (ethical and social considerations)' (Rowley, 2006, p. 1250). This is a sense of integrity, truth and reflection; understanding right and wrong; and self-interest is replaced with a sense of community and the greater good. Wisdom, therefore, provides ethical action

Goleman (1995) distinguishes between traditional views on intelligence, i.e., cognitive ability, and emotional intelligence, i.e., ability to manage emotional reactions in social situations (Salovey and Mayer, 1990). Wisdom, therefore, provides emotional control The Jewish religious concept "Tikkun Olam" combines with the state of Israel's specific political and economic contexts to provide Jewish people with desire change the world for the better (Kahane, 2012). Wisdom gained from "Tikkun Olam" and other religious philosophies, e.g., from Catholicism and Buddhism, may be described as enlightenment. Faucher et al., (2008) describe enlightenment as the highest form of understanding, and it is typically separated from the rest of the DIKW model. Enlightenment is not something to have; rather it is a state of being, such as existence (Faucher et al., 2008). However, religious wisdom can be practical. "Tikkun Olam" explains the Jewish desire to improve society, indeed to help repair it, and provides an incentive for action (Kahane, 2012). Wisdom, therefore, aims to improve society

The difference between wisdom and business ethics is the pursuit of evidence. Rather than simply following a moral code, Cicero (2005, pp. 18-19) argued that wisdom involves the weighing of evidence; and not wasting time on matters that are obscure, difficult or useless. Kaipa (2014) examined how wise decisions based on the Hindu concept of discrimination (viveka) led to ethical clarity. Viveka is the ability to perceive and make fine distinctions, i.e., judgements, and to value quality, i.e., evaluation, and is seen as part of spiritual discernment (Kaipa, 2014). Wisdom, therefore, involves judgement about moral conduct in things that matter based on interpretation of evidence, which creates eudaimonia

From an Eastern perspective, wisdom is grounded in Confucianism, Taoism and Buddhism, which are spiritual and religious traditions (Vermander, 2011). Chinese culture manifests in the moral relationship between people. This view promotes wisdom as having the virtues of flexibility, adaptation and far-sightedness. However, Vermander 2011: 701 argues that 'Chinese wisdom can easily be reduced to a vain and constant search for cosmic and social harmony, a search that may actually hide tensions and conflicts not allowed to come to the light of the day'. The two concepts of cosmic and social harmony are the clues to understanding Chinese wisdom. Cosmic harmony is socially expressed as a type of utopia that focuses on an imaginary past or place; a type of self-governing life process (Vermander, 2011). Social harmony is expressed as justice. In the West, we try to do justice to other people by recognising their rights to appropriate working and living conditions, e.g., through corporate social responsibility. Chinese wisdom, however, sees doing justice within a broader context. Social justice means listening to other people, and giving weight to what they say (Vermander, 2011); which is about respect and trust. Wisdom, therefore, involves relationships with others based on harmony and social justice 


\section{Table 2 Summary of retirees' wisdom}

\begin{tabular}{|c|c|c|c|}
\hline Theory & Concept & Findings & Type of Knowledge \\
\hline Episteme & Professional community & $\begin{array}{l}\text { - Knowing how to use discipline knowledge to create value for the } \\
\text { organisation } \\
\text { - Complex capabilities such as listening, communication, empathy, and } \\
\text { trust which enable team building and change management } \\
\text { - Mental models guiding behavioural decisions such as need for impact, } \\
\text { resilience, and self-awareness }\end{array}$ & $\begin{array}{l}\text { Technical } \\
\text { competencies }\end{array}$ \\
\hline Techne & $\begin{array}{l}\text { Personal judgement: } \\
\text { cognitive dimension }\end{array}$ & $\begin{array}{l}\text { - Focal wisdom is working with others (engineering and management), } \\
\text { and being more effective on the job (teaching and nursing) } \\
\text { - Subsidiary wisdom is socio-cognitive behaviours (business, teaching and } \\
\text { nursing) and making decisions (engineering) } \\
\text { - Individual wisdom is relationship skills (engineering, teaching and } \\
\text { nursing) and making a difference (business) }\end{array}$ & Technical practice \\
\hline Techne & $\begin{array}{l}\text { Personal judgement: } \\
\text { practical dimension }\end{array}$ & $\begin{array}{l}\text { - Understand the practical outcomes of your work in terms of being } \\
\text { recognised, respected, and trusted } \\
\text { - Recognition is being valued by colleagues as making a contribution } \\
\text { - Respect is being aware of the personal attributes that matter to you, e.g., } \\
\text { being a nice person, and aligning your behaviour with these attributes } \\
\text { - Trust is awareness of how to make a positive difference at work, e.g., } \\
\text { performance improvement }\end{array}$ & Practical outcomes \\
\hline Phronesi: affective & $\begin{array}{l}\text { Intellectual virtue: emotional } \\
\text { dimension }\end{array}$ & $\begin{array}{l}\text { - Helping others when asked } \\
\text { - Not competing with others for jobs or promotion } \\
\text { - Dealing with difficult people by understanding what they expect } \\
\text { from you } \\
\text { - Making complex decisions which may have a negative impact on people } \\
\text { (e.g., job cuts) rationally rather than emotionally }\end{array}$ & Emotional intelligence \\
\hline $\begin{array}{l}\text { Phronesis: } \\
\text { affective }\end{array}$ & $\begin{array}{l}\text { Ethical virtue: morality } \\
\text { dimension }\end{array}$ & $\begin{array}{l}\text { - Having the competency to pursue best practice (internal competition), } \\
\text { contribute to the performance of others including the organisation, and } \\
\text { generate approval by others } \\
\text { - Developing positive psychological contracts with the organisation } \\
\text { characterised by how to feel valued, useful, and appreciated } \\
\text { - Creating positive work relationships leading to accessing insiderness } \\
\text { (how to get ahead), accessing influential people (mentors/supporters), } \\
\text { and accessing social capital (working with people who can help your } \\
\text { career) }\end{array}$ & Moral conduct \\
\hline $\begin{array}{l}\text { Phronesis: } \\
\text { affective }\end{array}$ & $\begin{array}{l}\text { Ethical virtue: relational } \\
\text { dimension }\end{array}$ & $\begin{array}{l}\text { - Respect by empathising and valuing others } \\
\text { - Trust by empowering and listening to others, encouraging polite } \\
\text { disagreement (diversity of views), and not being confrontational or } \\
\text { judgemental (avoiding unnecessary conflict) }\end{array}$ & Relationships \\
\hline
\end{tabular}

Respondents differentiated between levels of discipline knowledge. Job-related knowledge learned at university was considered basic level. Retirees described this knowledge within the context of how it was applied, for example accounting:

"Management accounting looks inward on the business, financial accounting looks outwards. Management accounting helps the business more."

Advanced level knowledge emerged when retirees discussed how to use discipline knowledge to do a good job. For example, a good management accountant understands their internal customer:
"You have to know the business to use your technical skills to provide a solution for management; particularly information that helps them to make management decisions."

The type of work done by retirees helped identify whether were involved in complicated or complex tasks. When discussing the work they did over their careers, retirees focused on their most challenging roles rather than the technical aspects of the job. For example, a mechanical engineer described how he did engineering management, rather than mechanical engineering decisions. Most respondents talked about complex skills or capabilities rather 
than decisions. An accountant (business) felt that working with people was an advanced skill:

"The technical side is so easy, people are so difficult. That includes yourself, you can be difficult too."

Retirees felt the characteristics of being a good people manager included listening, communication, empathy, and trust. A general manager (business) felt his capacity to build strong teams was based on trust in the ability of others:

"If you want things only done your way, you are limited by yourself. You probably have talent working for you who would do things differently. Allow them to be creative, to make mistakes."

A general manager (business) discussed complex tasks in terms of being an innovator, which translated into a desire to make a difference: "having an impact was absolutely essential. It gave me job satisfaction, when I could see results improving". He needed impact to be measured by results, and this was based on cost improvements: "If our costs decreased but our productivity increased, we were improving."

Advanced level knowledge also emerged when retirees discussed personal characteristics which they felt made them good at their job. This was a unique capability which the retiree developed themselves. A special education teacher, i.e., for children with severe learning disabilities or behavioural problems, explained how basic technical knowledge was not enough:

"There was no course to prepare you for being a special education teacher."

A mental health nurse felt that she had "something in me" which she described as an individual talent. She explained how she had always been interested in people and over time became very aware of people's behaviours and feelings. She felt this talent was very important because it helped her do her job well.

The highest level of technical competency revealed by the retirees was behavioural decisions. A mental health nurse explained:

"Knowing myself I think is really important. You have to know how you react in situations; what situations you like, what situations you are comfortable in, because that allows you to make the decision to learn to deal with that or to say no I am not going to deal with that. Knowing what it is about other people that is going to push your buttons that means that you can't work properly so that you can work properly. It gives you choices, and I think life is about choices".

This describes a high level ability to function effectively in varying complex social situations. In the earlier discussion, retirees described how "people skills" is an advanced level of technical competency. Decisions about how to adjust behaviour according to social interaction seems to be a highly complex task.

\section{Techne: personal judgement}

Practical dimension. This is judgements about skilful knowing validated by organisational knowing, i.e., the social collective (Pinheiro et al., 2012). This is about applying knowledge. It involves personal judgements about whether the individual feels they are doing things right. It has an 'others' focus. It leads to respect and trust from others about the individual and their work.

This paper proposes that wisdom enables higher level or more useful application of knowledge. The method used in this section to separate levels of knowledge usage is to examine the outcomes. This involves understanding individual action in terms of what they were trying to achieve.

Retirees' expected outcomes for using their knowledge began with reputational impact. Retirees defined this as job-related reputation. A respondent wanted to be remembered as a good nurse, however, she felt this was not easy because - "everyone has a different definition of what is a good nurse". Some retirees discussed the importance of being valued by colleagues. An engineer said "I'd like to be remembered as someone who never let the team down." An accountant (business) hoped "people would recognise my contribution."

Retirees then discussed personal reputation. The most important outcome was respect. An engineer said he wanted people to remember him "Just as (his name), the individual, whether good or bad, not the job, the individual." Another engineer wanted to be known as a nice person: "to men he was a good bloke, and to ladies he was a gentleman, that is how I'd like to be remembered." A nurse wanted to be remembered "as a person who gave it a go, and gave it her best".

The second personal reputation outcome was trust. Trust was defined as the impact made at work, i.e., whether they could be trusted to do good work. A nurse felt she had made a contribution-"I made some changes", and had a positive influence on others- "I mentored others along the way...I guess it's one of the things that I love the best." A general manager (business) said "I'd like to be remembered as someone who created a positive culture in the workplace. Someone who changed the culture."

Cognitive dimension. This is the capacity to resolve complex problems (Minsky, 1985). This is about applying experience. It involves personal judgements about whether the individual feels they are doing the right thing. It has an 'internal' focus. It leads to individual internal evaluations about their work performance.

Polanyi felt that tacitness enables us to do things without thinking about them (Ray, 2005, p. 4). We may know how to do something in practice but find it difficult, perhaps impossible, to explain how we do it (Tsoukas, 2003). Researchers have argued that only during the act of doing can others learn tacit knowledge from an individual (Tsoukas, 2003). This emphasises the importance of context, which this paper defines as technical practice (techne's cognitive dimension). The analysis classifies the knowledge in terms of focal awareness, subsidiary awareness and the unique perspective of knower. Focal awareness was what came into the retiree's head, i.e., consciousness, when they tried to remember situations when they did their most valuable work. Subsidiary awareness was other related knowledge which the retiree became aware of, i.e., surfaced from subconscious, when they were rediscovering how they did this work. The knower's perspective was the retiree's individual capabilities which they applied to the work situation.

Figure 2 summarises technical practice by discipline in terms of knowledge and wisdom. Each discipline has two rows. The top row represents knowledge. It is a summary of the retirees' views on what a good engineer (for example) needs to know to do good work, i.e., skilful knowing. It is measured against the respondents' perception of their community and is the techne practical dimension. The bottom row represents wisdom. It is a summary of the retirees' views about how skilful knowing emerged in their careers and is the techne cognitive dimension.

\section{Phronesis: cognitive}

Behavioural dimension. This paper proposes that wisdom enables a higher level or more mature behaviour. The method used to separate levels of behaviour in this section is to examine ethical action in terms of right and wrong. Plato interpreted knowledge as true judgement (Jashapara, 2011). Judgement allows the individual to find evidence or proof based on their answers to internal questions. This section examines how retirees developed their sense of internal integrity.

First were assumptions about the nature of work. Some retirees were highly critical of declining standards in their discipline; for 


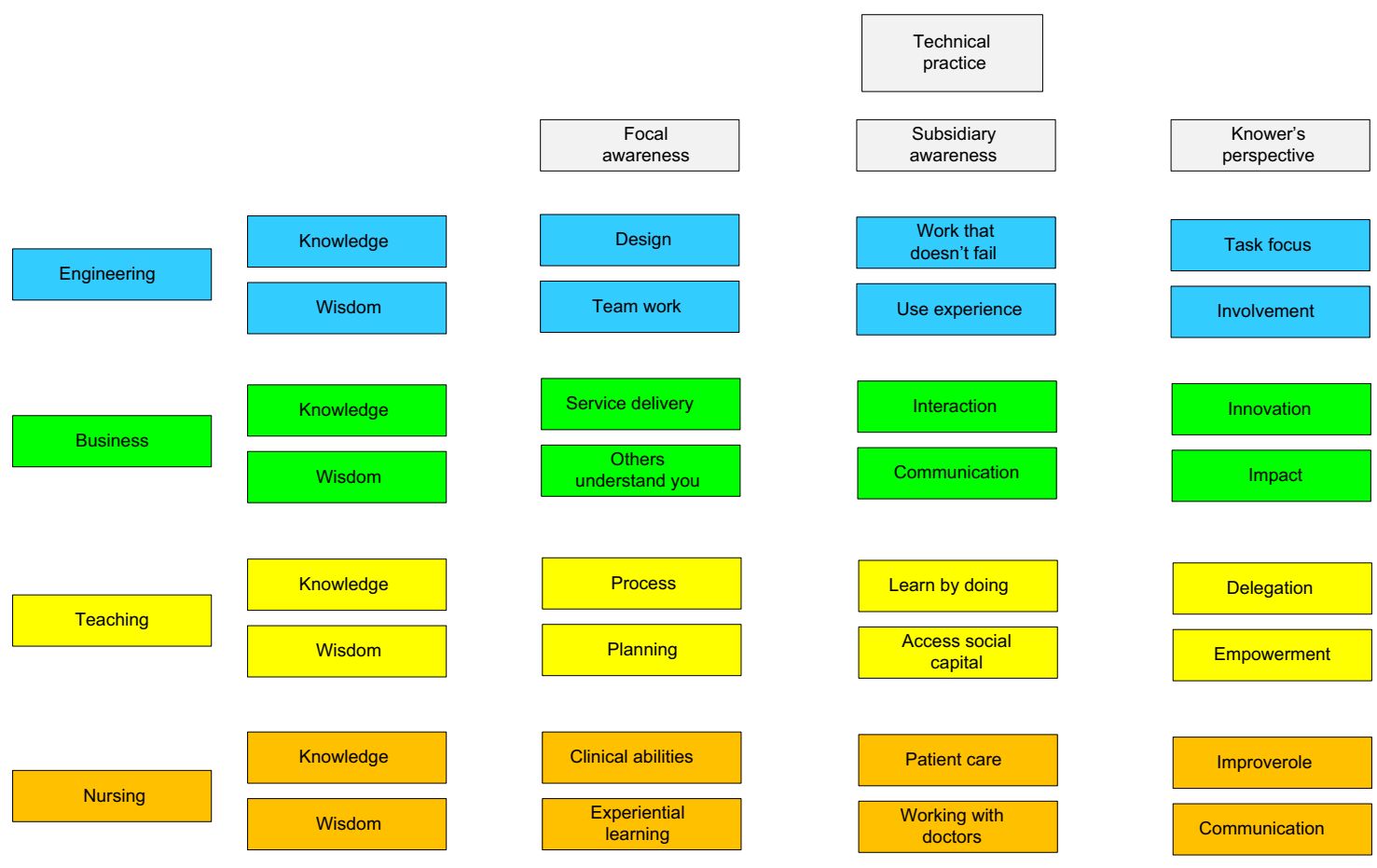

Fig. 2 Summary of retirees' knowledge: cognitive decisions technical practice

example a nurse felt strongly about the current practice of extending a patient's life and that is was not always right. Second were expectations of other people. An engineer felt it was important for people to be genuine at work:

"The best people, their natural behaviour shone through, they weren't trying to impress anyone, they treated everyone the same. They were good people managers."

Another engineer explained "You soon find out what people are really like, their true personality." Therefore, retirees' internal mental models of right and wrong begin with standards of behaviour in terms of work and people.

Third was combining these expectations of work and people, i.e., standards of integrity, to make complex decisions. This involved two types of ethical action: effective delegation and performance evaluation. A general manager (business) explained how he relied upon his staff to develop solutions to their business problems because he trusted them and he knew they understood their business best: "My role was to point out the cost and how it must be reduced; they found the solution."

A nurse explained how she interpreted an individual's behaviour in performance appraisal situations and selection panels:

"Someone who gets good feedback that they don't make a lot of errors in what they're doing. They talk to other people so they don't hide what they are doing. They know they are very ethically aware of right and wrong and they're aware of their boundaries and boundary violations. They're knowledgeable and their practice is grounded in theory and in research."

The fourth step in understanding retirees' ethical action was to consider how they discovered truth about what is right and wrong. This involved how they made good decisions. A general manager (business) explained how he determined whether a problem was legitimate. In a support services business, complaints may be part of organisational politics or other illegitimate causes. The ability to clarify this ambiguity was important:

"You had a performance ambiguity issue, if something didn't work, why didn't it work? For example, why did the contracting business not do the job on time? They might blame others. If it is legitimate, you look at it and ask why, and often you could improve it."

A nurse explained the choices she made about restrictive environments, such as whether to openly oppose them:

"It's probably better not to always say what you think. That comes with maturity and learning."

\section{Phronesis: affective}

Emotional dimension. A further method used to separate levels of behaviour is to examine ability to manage emotional reactions in social situations (i.e., control); and listening to other people, and giving them respect and trust (i.e., social justice); replacing self-interest with sense of community and the greater good (i.e., ethical action); This section will evaluate whether retirees have higher levels of control, social justice, and ethical action.

This paper uses sensemaking to examine emotional control. Sensemaking may be classified as knowing that and knowing how (Jashapara, 2011). 'Knowing that' is the capacity to understand that something has happened or is happening, i.e., an event. This is tied to the concept of realism (e.g., see Hawking and Mlodinow, 2010). 'Knowing how' is the cognitive ability to determine causal relationships surrounding the event: what happened before and after the event? This leads us understand the process explaining how the event occurred (Jashapara, 2011). These processes help us predict and manage our world. Higher levels of sensemaking create better understanding of the reality of work and the capacity to understand complex social situations and know how to behave rationally rather than emotionally.

An engineer explained how it was important to demonstrate work performance:

"People will judge you from different perspectives. All organisations I've worked for look first at your professional skills, and then how well you put those skills into practice."

Being seen as a good performer helped becoming accepted by management and also other staff and, therefore, welcomed into teams. In this case, 'knowing that' sensemaking involved realising the type of work performance necessary to be accepted. 
Acceptance also involved understanding the organisational culture. Some retirees reflected about an earlier era:

"The amazing thing was there was always someone to ask, and they'd give it to you willingly. They were a marvellous generation the WW2 generation, they'd been through a lot, and so they helped you. It was just the way it was done, you helped the younger people who came to you."

The organisational culture of that time was also defined by the job security provided by management:

"It was a mateship culture. What is destroying things today is this cut throat business environment. We never had to worry about our job, we knew we would have a job for as long as we wanted it; you had a house, and you could pay it off.

Another engineer felt that lack of ambition helped him:

"I was never ambitious. Ambitious people forget the present, they're too concerned about where they want to go. My concern was always-what I was doing-I was doing well."

This also sent messages to rivals that he was not competing with them for promotion, making him less threatening and, perhaps, less open to the negative forces of power and politics.

However, the retirees also acknowledged there were complex social situations when they needed to develop ways to deal with difficult people. An accountant (business) explained how he dealt with demands placed on him by management:

"Pressure to falsify (creative accounting) happens all the time, it is part of the job but you have to manage it. I would give them options and make them aware of the consequences. That way I passed all responsibility and accountability onto them."

A special education teacher had to ensure her students did not disrupt the 'normal' children or their teachers:

"I was seen to be doing a good job if I was controlling the children because they had behaviour problems. As long as the children played amicably in the playground. I had no real performance reviews, I just had to keep the class quiet."

A general manager (business) explained how he made complex decisions about workforce planning:

"We had to cut staff. We had a planning meeting and decided we had too many managers and supervisors. We discussed what do we need to deliver, and we decided on the structure to deliver it. When reducing costs, a significant bulk of the cost was management. It was trying to distinguish between who brought the money in and who didn't. We still needed a certain level of supervision but we used teams and minimal supervision."

The 'knowing how' in this sensemaking was driven by the causal relationships in his desired outcome, i.e., cost savings, and how to achieve it, i.e., reducing staff numbers. He also explained how his sensemaking was used in negotiating with unions about staff cuts:

"The unions will object to staff cuts. So you've got to negotiate, so you start with more than you expected and work back towards what you'll accept. Make them feel good that they've won some ground by asking too much at the start and letting them fight back. Negotiation is about working to a solution, it may not be the one you want, but it is better than you've got."

Societal change dimension. This section involves understanding individual action in terms of whether retirees wanted to improve society. Retirees' need to have a lasting legacy is explored within the concept of “Tikkun Olam" (Kahane, 2012). The retirees' professions - engineering, business, teaching, and nursing, provide an interesting contrast in terms of "Tikkun Olam". Teaching and nursing provide essential services for society-education and health careand these generate social value. Engineering and business create infrastructure and jobs and these generate economic value.
However, the study found limited evidence of trying to repair society, i.e., "Tikkun Olam" amongst retirees. A nurse revealed frustration that she did not achieve her goal of being remembered as a good nurse. Her internal conflict about the impact she had over her career was probably because the value of nursing is not clearly defined. The engineering and business respondents did not reveal societal goals. Rather than creating economic value for society, e.g., jobs, their focus was on how to generate internal value via performance improvements and cost reductions (including cutting jobs). Therefore, their goal was to help repair their organisations, rather than society.

The only respondents who revealed a sense of "Tikkun Olam" were teachers. The retired teachers gained great personal satisfaction from the impact they had on students and their families. The special education teacher spent her career ostracised by her peers. However, she felt proud when discussing some of her students she had met again when they had become adults and how they had found jobs and independence. She focused on these outcomes as internal justification for a difficult job and career. Another teacher felt his greatest impact was early in his career when he worked at a school in Africa for local communities. $\mathrm{He}$ remembered a question from a young boy - "why do white people have all the brains?" It summarised a period of his life when he felt he was really making a difference to the lives of people. This desire to improve the world around him continued throughout his career.

Morality dimension. This paper proposes that wisdom enables a higher level or more advanced type of moral conduct. The method used to separate levels of moral conduct is perception of success. Individuals make decisions about their conduct at work based on an internal moral code which is driven by their desire to perform well. People with wisdom perceive success differently to others. They make good decisions guided by judgement about right and wrong. This morality enables an inner calm and personal satisfaction leading to eudaimonia (feeling happy about life). Therefore, the desire to feel happy at work, i.e., job satisfaction is related to higher levels of moral conduct, which creates a feeling of career success. This section examines retirees' views on what made them successful in their careers. In doing so, it aims to evaluate whether retirees have a higher moral code and, if so, whether this contributed to their sense of career success.

Moral conduct wisdom begins with discernment and fine distinctions about what is important. Some retirees began their reflection on what made them successful by discussing specific competencies. The respondents looked at this topic very differently. The teachers focused on the core practice of teaching itself: "we did terrific mathematics". Their measure of success was how other schools regarded them: "the high school was very complimentary of how well prepared students were (from primary school)". A teacher was proud of the jobs her students had when they grew up. Their moral code was related to reputational impact, where they wanted others to reflect positively on the quality of their teaching process rather than content.

A general manager (business) also focused on his impact on others:

"At the workplace, people should enjoy what they're doing, understand where they're going, and understand when they're achieving things. I don't believe in micro managing, I believe in challenging people, and allowing them to grow".

His moral code was driven by empowering others and making a positive impact on his organisation. The teaching and business retirees had a genuine desire to help others. 


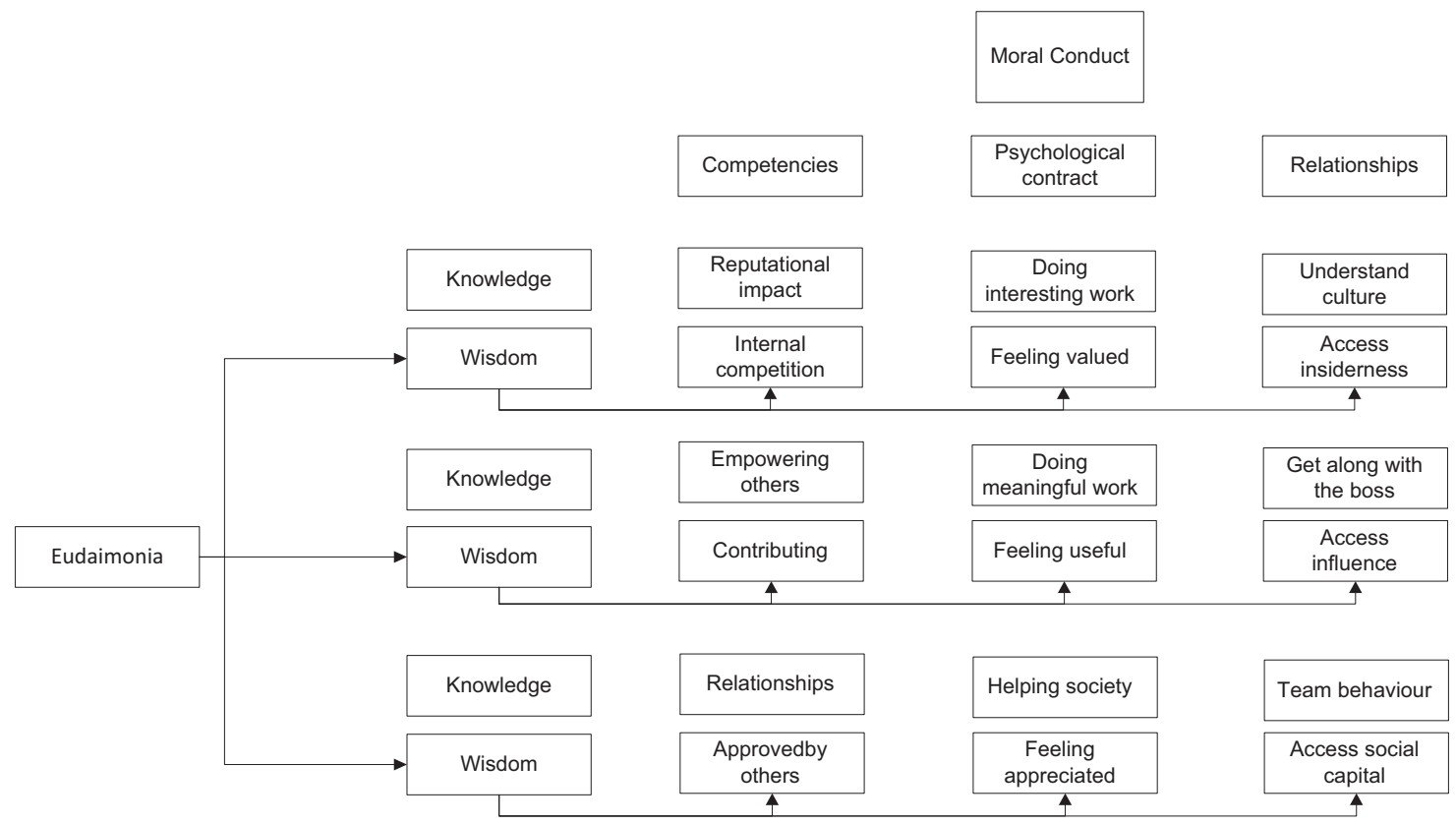

Fig. 3 Summary of retlrees' knowledge: cognitive decisions moral conduct

In nursing, the focus was more internal. This nurse explained how her success was due to self-confidence, getting along with people, and delivering results:

"I think that understanding of myself, knowing that I've got something to give, I'm not frightened of failure, I'm willing to put myself forward for something and even if it's something that I don't believe I know a lot about, I'm always ready to give it a go and give it my best go. I guess I must have produced what people wanted. I think also because I am not a person who ruffles feathers so I can work with people. It leads to somebody saying oh yes that person can do that we'll give them a go."

Like the teachers, her moral code was driven by how others perceived her. There is a sense that she wanted to be liked by others and approved by them.

These cases illustrate three different types of moral conduct. The business respondent appears to be driven by an external sense of honourable conduct, i.e., helping others, and success is measured in terms of whether he feels satisfied with the performance of his staff and organisation. His Eudaimonia is generated by his contribution. The nursing respondent appears to be driven by an internal sense of honourable conduct, i.e., whether others will respect her conduct. Her Eudaimonia is generated by others' approval. The teaching respondents appear also to be driven by an external sense of honourable conduct, i.e., helping others. However, they also want to be recognised by their peers. Their Eudaimonia is generated by internal competition.

Some retirees reflected on what made them successful by discussing their work. The literature on job satisfaction is based on psychological contract theory; which is the emotional relationship between the individual and employer and measures organisational commitment (Massingham and Diment, 2009). Psychological contract may be understood within the motivational processes of social exchange theory and the norm of reciprocity (e.g., Blau, 1964). Retirees' wisdom may be expressed as having deeper awareness of their psychological contract with their employer. An accountant (business) explained how being given interesting work made him feel valued. A general manager (business) had strong a desire to find meaning and purpose in his work. A teacher discussed her impact on the local community:
"I enjoyed that because that's where I was brought up. I knew a lot of the parents. It gave me a great deal of satisfaction that relationship."

The Eudaimonia of these respondents is generated by being valued and feeling useful. Their psychological contract increased if their organisations gave them work which met these needs. In return, they would give their organisations higher levels of moral conduct.

Retirees also discussed their career success in terms of relationships with other people. Some respondents focused on pleasant memories of the people they worked with: an engineer said "all through work I never had a bad boss". Another engineer explained the importance of cultural fit: "if you fit in well, they are supportive". A nurse told how her early career success was due to "the relationships that I built with people". She described the importance of working with others:

"I don't think that people ever do anything by themselves I think it's always a group of people, although we are individuals, we work very much as a group and it's the group that achieves something rather than the individual."

These respondents' Eudaimonia is generated by having positive social networks at work, i.e., being liked and liking people. However, this type of wisdom is not about how to make friends at work. It is about knowing how to fit in (understanding culture), getting along with the boss, and behaving in a team. These retirees knew that if they learned these things, they would have strong work relationships, which they desired. The difference between social capital, i.e., relational knowledge, and relational wisdom is the type of relationships. Wisdom creates the right type of relationships with the right type of people, as explained by this nurse:

"I was given the opportunity to learn from others and to work with people with similar interests".

In return for higher moral conduct in working relationships, their organisation was willing to give them the opportunity to work with people who can help them become successful in their careers.

Figure 3 summarises moral conduct by discipline in terms of knowledge and wisdom. The typology of knowledge represents retirees' moral codes in the three areas which emerged from the 
research: competencies, psychological contract, and relationships. This is what drives honourable behaviour, i.e., doing the right thing at work. The typology of wisdom represents retirees' Eudaimonia, i.e., their happiness from work conceptualised as career success.

Relational dimension. Another method used to separate levels of behaviour in this section is to examine harmonious personal relationships in terms of social justice, i.e., giving people respect and trust.

Retirees agreed that relationships at work are important. A nurse explained that relationships are a normal part of working:

"You have to work as a team. If you're not a team worker you still have to work within a team so those relationships are very important. When those relationships break down, the team doesn't work so well and the end result reflects on everyone."

A general manager (business) also felt that relationships were essential to get the job done- "you don't possess all the skills you need", and productivity - "to get the best out of your team."

When discussing how to build effective relationships, several competencies emerged. The first was empathy. An accountant (business) explained that empathy begins by taking an interest in the other person:

"You get personal with people. Find out what each other thinks and does."

A nurse explained how she focused on the other person:

"I talk to people. I am happy for people to always come in and talk to me. They would tell me a bit about their lives. I could ask them about their family, and because I observe behaviours, I could see changes in people. I could ask them if there was something wrong or what was happening, were they ok. Well, I am really interested in people."

An engineer explained how the migration of people from Europe after WW2 provided the opportunity to meet people from other cultures and develop relationships with them:

"One of the best parts of my career was meeting the people who came here from overseas. Everyone got along. You'd get to know them socially, great hospitality."

Therefore, social justice wisdom begins with liking other people and focusing on them rather than yourself during social interactions. An engineer explained how it also involves being polite:

"I never talked down to people. I would say good morning every day, ask how their families are."

Another engineer explained the importance of valuing others:

"You work with people across the organisation but the guy pushing the broom is no different, everyone has value. Everyone wants to contribute something. There is nothing worse than people treating people differently because they are at a different level, they are people, they're just doing a different job."

Therefore, social justice wisdom's concept of respect has two characteristics: empathy and value. The capacity to like other people and value them enabled respectful relationships at work.

Retirees described several competencies necessary to build trust. The first was empowerment. An engineer explained how it was important to praise his staff to management:

"Upper management realised what a good job they're doing, how important they were to the company, and how dedicated they were."

A general manager (business) described the second trust competency as encouraging polite disagreement. He felt the "management of agreement" was encouraged by leaders who pretended to seek social harmony, but were really simply trying to be popular. This was ineffective because it discouraged diversity of opinion and creativity. He felt that "some bosses want you to say yes to what they say, even if it is wrong." However, he believed that "a good boss will encourage disagreement because he/she knows we have different perspectives." He explained polite disagreement meant that "you don't need complete agreement or cohesion to have good working relationships."

The third trust competency was avoiding unnecessary conflict. A general manager (business) explained that it was important not to been seen as confrontational:

"You can't afford to be viewed as someone who is confrontational. People won't speak to you or they won't come to you with tricky matters. It is important that people do come to you, particularly if in a management role. If people have a problem, they want you to listen to them. They don't necessarily want you to solve the problem but they look for some empathy."

He explained that the art of listening was based on not criticising others:

"Don't judge people-it is so easy to say you're wrong or don't do that."

\section{Discussion}

By aiming to improve understanding of the concept of practical wisdom, the paper deconstructed thinking about practical wisdom (see Chia, 1995, p. 591). This paper aimed to identify whether retirees had wisdom and, if so, what this was. The paper's underlying assumption is that wisdom is a higher level of sociocognitive understanding, i.e., see the DIKW hierarchy (Ackoff, 1989). It makes a further assumption that wisdom is attained through experience and what differentiates knowledge and wisdom is the depth of understanding provided by experience. Retirees, therefore, should have wisdom based on experience accumulated over a career. Table 2 summarises the findings against the conceptual framework (see Fig. 1).

Thompson (2017) provides an opportunity to compare the results of this paper with previous research. Thompson (2017) defines five constructs as decision making wisdom:

- "Rational and analytical capability: capability to use reason, logic, and intellect in order to gain a greater knowledge of a situation and apply the knowledge more quickly or efficiently. - Intuitive insight: gut feel or the non-rational dimension.

- Values/human character: beauty, truth, goodness, humanity

- Self-awareness: voice within, higher consciousness, reflection

- Emotional regulation: humility, generosity, empathy, calm" (2017, pp. 219-225)

Table 2 defines retirees' practical wisdom in terms of this paper's conceptualisation of wisdom (see Fig. 1). The dimensions represent the evidence of retirees' wisdom in each of the conceptualisation's categories. The dimensions fit with Thompson's (2017) typology as follows: Thompson's rationality aligns with this paper's episteme and techne practical dimension; Thompson's intuition aligns with techne's cognitive dimension; Thompson's values aligns with Phronesis's affective morality dimension; Thompson's self-awareness aligns with Phronesis's cognitive behavioural dimension; and Thompson's emotional regulation aligns with Phronesis's affective emotional dimension. This paper's two remaining dimensions (ethical virtues) Phronesis's affective societal change dimension and relational dimension are not included in Thompson's framework and are new constructs.

The findings reveal nuances in retirees' wisdom which may be captured in broad terms as lessons learned. This nuance was most evident in techne's cognitive dimension (technical practice) and phronesis's affective morality dimension (moral conduct). Technical practice focal knowledge included clinical nursing (curiosity), engineering design (drawing), engineering management (use 
experts to fill gaps), accounting (help non-accountants interpret numbers), general management (communicate strategy), and teaching (differentiated learning). Subsidiary knowledge included clinical nursing (sensing illness) and mental health nursing (experiential learning), engineering design (instinct), university/ industry partnerships (incentives/benefits), business leadership (walking around, talk at their level), and teaching (preparation). Individual knowledge included clinical nursing (career management), mental health nursing (self-awareness, learning by doing, communication), engineering management (practical approach, management by getting involved, getting others involved), business (improvement, managing change), business leadership (making an impact, rather than compliance, supporting the business), teaching (delegating, empowering). The findings about moral conduct explained how to behave at work. First, respondents talked about their sense of appropriate behaviour at work or how to fit in with the organisational or job culture (norms) or be seen to be doing a good job (values). Norms included cooperation, integrity and ethics, avoiding conflict with others, and being honest about work performance. Values included a strong work ethic (being busy), being helpful, and good communication. Second, some discussed their unique perspective about the type of behaviour that worked for them. This included tackling difficult problems, sharing responsibility, being innovative, being popular, focusing on doing the current task well, finding good people for your team, and willingness to learn from others. These lessons learned most capture the nuances of practical wisdom of these retirees.

\section{Conclusion}

This paper aimed to improve understanding of the concept of practical wisdom by focusing on Aristotle's concept of practical knowledge. The paper examined the type of knowledge accumulated by retirees' over a lifetime in the workforce. Wisdom is gained from a process of pedagogical thinking and reasoning (Ellett, 2012, p. 12); and is the outcome of interactions between general (theory) and practical (judgement) (Ellett, 2012, p. 14). Aristotle felt that practical matters, such as those faced at work, requires practical knowledge (Tsoukas and Cummings, 1997). This paper contributes to the understanding of professional practice knowledge.

The conceptual framework (Fig. 1) was enriched through the empirical study. There were several findings. First, people with wisdom make better decisions. This paper proposed that wisdom enables a higher level or more advanced type of decision making. This view of wisdom builds on the reflective practitioner as a framer of problems (Schon, 1983). Whereas episteme's technical knowledge may address complicated tasks, techne's wisdom enables people to resolve truly complex tasks (see Fig. 2). People with wisdom also perceive success differently. They make decisions guided by judgement about right and wrong. Techne provides personal judgement which enables the professional to judge their actions from an external and internal perspective. Techne's practical dimension allows recognition by others which validates the individual's work and creates trust and respect in their capability. Techne's cognitive dimension enables internal awareness that the work is being done well according to the individual's perception of best technical practice (see Table 2). Knowing that others and the individual themselves are happy with the quality of their work creates a morality that enables an inner calm and personal satisfaction leading to eudaimonia (feeling happy about life).

Second, people with wisdom behave differently. This paper proposed that wisdom enables a higher level or more mature behaviour. Phronesis has two properties: cognitive and affective which provide intuition about to behave appropriately in different situations. Phronesis's cognitive properties create awareness of the knowledge that may be trusted to be seen to be behaving normally or appropriately in the organisation, i.e., fitting in with the culture (see knowledge rows in Fig. 3). Phronesis's affective properties has four dimensions (see Table 2). The first of these dimensions, the emotional dimension, creates empathy for others; which emerges in harmonious personal relationships and a focus on helping the organisation and society (see Table 2). This is ideal moral conduct creating a sense of eudaimonia (see wisdom rows in Fig. 3). These two Phronesis properties, cognitive and affective, are intellectual virtues.

Third, people with wisdom are motivated differently. This paper proposed that wisdom enables higher level or more useful motivation to use their knowledge. Phronesis's affective remaining three dimensions (see Table 2) involves the individual wanting to make a significant difference from their work. This might emerge in desire to change or improve (societal dimension), the individual's self-identity (morality dimension), and how they measure their impact with others (relational dimension). These three Phronesis affective properties are ethical virtues, which emerges in the individual's need to have a lasting legacy, which might mean their view of respect, trust, and reputation.

The paper's limitations are that the findings are based on nine individual case studies. While this may appear to be a small data set, the findings are based on more than $40 \mathrm{~h}$ of face-to-face interviews. The paper may be seen as an introduction to discover relationships between what retirees can articulate when asked to describe the knowledge gained over their career, and how this may be interpreted in terms of an Aristotelian conceptualisation of practical wisdom. Whether the conceptual framework by itself allows generalisations on practical wisdom depends on the reader's epistemology. The paper is written from a constructivist perspective where theorising from case studies (e.g., qualitative research) is allowed. The findings provide exciting opportunities for further research across all epistemologies. The conceptual models in Figs. 1, 2, and 3 may be investigated with retirees in other disciplines. There is also opportunity to examine the detailed findings further. Table 2 findings may be tested. The results also generate specific research topics. For example, there is an interesting opportunity exists to examine the eudaimonia within the context of being valued and feeling useful. Further research might examine whether this sense of eudaimonia and moral conduct changes over the timeframe of a career.

\section{Data availability}

There is no publicly available datasets for this publication.

Received: 11 September 2018; Accepted: 29 August 2019; Published online: 22 October 2019

\section{References}

Ackoff RL (1989) From data to wisdom. J Appl Syst Anal 16:3-9

Bierly III PE, Kessler EH, Christensen EW (2000) Organizational learning, knowledge and wisdom. J Organ Change Manag 13(6):596-618

Blau PM (1964) Exchange and power in social life. Wiley, New York

Bredillet C, Tywoniak S, Dwivedula, R (2014) Reconnecting the theory and practice in a pluralistic organizing context: issues and Aristotelian considerations, 14th EURAM Conference Proceedings, Valencia, Spain, 4-7 June 2014

Chia R (1995) From modern to postmodern organizational analysis. Organ Stud 16 (4):579-604

Cicero (2005) Cicero De Officiis On Duties, Loeb Classical Library, Harvard University Press, Cambridge (trans: Walter Miller)

Eikeland O (2008) The ways of Aristotle: Aristotelian Phrónêsis, Aristotelian philosophy of dialogue, and action research, Studies in vocational and continuing education (5), Peter Lang, Bern 
Ellett Jr FS (2012) Practical rationality and a recovery of Aristotle's 'Phronesis' for the Professions, Ch. 2. In: Pitman A, Kinsella EA (eds) Phronesis as professional knowledge: practical wisdom in the professions. Sense Publishers, pp. 13-34

Faucher J-BPL, Everett SM, Lawson R (2008) Reconstituting knowledge management. J Knowl Manag 12(3):3-16

Gavrilova T, Andreeva T (2012) Knowledge elicitation techniques in a knowledge management context. J Knowl Manag 16(4):523-537

Goleman D (1995) Emotional intelligence: why it can matter more than IQ. Bantam Books, New York

Habermas J (1971) Knowledge and human interests (trans: Shapiro, JJ) Beacon Press, Boston

Hacking I (2002) Inaugural lecture: chair of philosophy and history of scientific concepts at the College de France, 16 January 2001. Econ Soc 31(1):1-14

Hawking S, Mlodinow L (2010) The grand design: new answers to the ultimate questions of life. Bantam Press, London

Higgs J (2012) Realising practical wisdom from the pursuit of wise practice, Ch. 6 . In: Pitman A, Kinsella EA (eds) Phronesis as professional knowledge: practical wisdom in the professions. Sense Publishers, pp. 73-86

Jashapara A (2011) Knowledge management: an integrated approach. Pearson Education. Prentice Hall, Essex, England

Kahane B (2012) "Tikkun Olam": how a Jewish ethos drives innovation. J Manag Dev 31(9):938-947

Kaipa PL (2014) Making wise decisions: leadership lessons from Mahabharata. J Manag Dev 33(8/9):835-846

Kondrat ME (1992) Reclaiming the practical: formal and substantive rationality in social work practice. Soc Serv Rev 166:237-255

Macklin R, Whiteford G (2012) Phronesis, aporia, and qualitative research, Ch. 7. In Pitman A, Kinsella EA (eds), Phronesis as professional knowledge: practical wisdom in the professions. Sense Publishers, pp. 87-100

Massingham P, Diment K (2009) Organizational commitment, knowledge management interventions, and learning organization capacity'? Learn Organ 16 (2):122-142

Minsky M (1985) The society of mind. Simon \& Schuster, New York

Pinheiro P, Raposo M, Hernandez R (2012) Measuring organizational wisdom applying an innovative model of analysis. Manag Decis 50(8):1465-1487

Ray T (2005) Making sense of managing knowledge, Ch. 1. Managing knowledge: an essential reader, In: Little S, Ray T (eds) Sage Publications, London, pp. 1-20

Revans R (1980) Action learning: new techniques for management. Blond \& Briggs, London

Rowley J (2006) What do we need to know about wisdom? Manag Decis 44 (9):1246-1257

Salovey P, Mayer J (1990) Emotional intelligence. Imagin, Cognition Personal 9 (3):185-211

Schon D (1983) The Reflective. Practitioner. Basic Books, New York

Thompson M (2017) How managers understand wisdom in decision making: a phronetic research approach, Ch. 9 in Kupers W, Gunnlaugson O (eds) Wisdom learning: perspectives on wising up business and management education, Routledge, London and New York, Taylor \& Francis, pp 211-228
Tsoukas H (2003) Do we really understand tacit knowledge? Ch. 21. In: EasterbySmith M, Lyles MA (eds) Handbook of organizational learning and knowledge management. Blackwell Publishing, Hong Kong, pp 410-427

Tsoukas H, Cummings S (1997) Marginalization and recovery: the emergence of aristotelian themes in organization studies. Organ Stud 18(4):655-683

Van de ven AH, Johnson PE (2006) Knowledge for theory and practice. Acad Manag Rev 31(4):802-821

Vermander B (2011) Chinese wisdom, management practices and the humanities. J Manag Dev 30(7/8):697-708

\section{Acknowledgements}

The author wishes to acknowledge the University of Wollongong Global Challenges programme for providing a small grant in support of this research, as well as the contributions of the following people who participated in the broader research project: Anil Chandrakumara, Susan Sumskis, Roger Lewis, Richard Fleming, Christa Wood, Rodney Clarke, Siobhan McHugh, Colin Greig, Paul Chad, Linda Dawson, Julie Francis.

\section{Competing interests}

The author declares no competing interests.

\section{Additional information}

Correspondence and requests for materials should be addressed to P.M.

Reprints and permission information is available at http://www.nature.com/reprints

Publisher's note Springer Nature remains neutral with regard to jurisdictional claims in published maps and institutional affiliations.

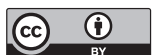

Open Access This article is licensed under a Creative Commons Attribution 4.0 International License, which permits use, sharing, adaptation, distribution and reproduction in any medium or format, as long as you give appropriate credit to the original author(s) and the source, provide a link to the Creative Commons license, and indicate if changes were made. The images or other third party material in this article are included in the article's Creative Commons license, unless indicated otherwise in a credit line to the material. If material is not included in the article's Creative Commons license and your intended use is not permitted by statutory regulation or exceeds the permitted use, you will need to obtain permission directly from the copyright holder. To view a copy of this license, visit http://creativecommons.org/ licenses/by/4.0/.

(C) The Author(s) 2019 